Rizova, E., Bekar, M., \& Velkovski, Z. (2020). Educational challenges of roma minorities: The case of the Republic of North Macedonia, International Journal of Cognitive Research in Science, Engineering and Education (IJCRSEE), 8(3), 113-122.

Original scientific paper

UDK:

Received: November, 01.2020.

Revised: November, 28.2020.

Accepted: December, 07.2020.

doi: 10.23947/2334-8496-2020-8-3-113-122

\title{
Educational Challenges of Roma Minorities: The Case of the Republic of North Macedonia
}

\author{
Elena Rizova ${ }^{1 *}$, Mira Bekar², Zoran Velkovski ${ }^{1}$
}

\begin{abstract}
${ }^{1}$ Faculty of Philosophy, Ss.Cyril and Methodius University - Skopje, Republic of North Macedonia, e-mail: elenarizova@fzf.ukim.edu.mk; zoran@fzf.ukim.edu.mk

${ }^{2}$ Faculty of Philology, Ss.Cyril and Methodius University - Skopje, Republic of North Macedonia, e-mail: m.bekar@flf.ukim.edu.mk
\end{abstract}

\begin{abstract}
Linguistic diversity comes in various forms. The most common ways of developing knowledge of more than one language according to some authors are either by learning a second language through participation in some form of bilingual education or being raised in a bilingual environment, such as school or a bilingual family. The phenomenon of development of literacy competencies of minority groups, specifically, the context of Roma people, in the Republic of North Macedonia, whose mother tongue is not even considered a standard language is the main research purpose of this paper. Research conducted in comparative studies on integrated education shows that in the elementary schools with high numbers of Roma students actions are rarely taken to enhance the integration of these minority students, because of 1 ) the lack of iconography, which is important for the ethnic identity of this minority and 2) low competence level of parents and teachers who are not adequately trained to work with students coming from different linguistic backgrounds or social backgrounds that are characterized by low literacy levels and low learning competences. Participants in this study were from several primary schools in North Macedonia and the responses were categorized according to the major themes that occurred. The findings show how women are excluded from obtaining better education and that multilingual children from deprived economic settings with poorly educated parents struggle and are seriously challenged to obtain proper literacy and education in elementary schools. The study reveals important details about the educational legislation, treatment of Roma people by local and international organizations and provides suggestions for improvement of the current status of the Roma population.
\end{abstract}

Keywords: Roma people, biliteracy, unequal educational opportunities, ethnicity education, literacy practices.

\section{Introduction}

People speak more than one variation of the languages that are official and non-official in some countries. Such is the case with the Republic of North Macedonia where the official language is Macedonian, while in areas where more than $20 \%$ speak a certain language, such is the case with the Albanian population, makes the language a second official language. The second official language is fully used in all institutions (Government, Parliament, in documents, official correspondence). The other languages of minorities in R. N. Macedonia are Turkish, Romani, Serbian, Aromanian/Vlah and Bosnian. These languages of minorities and language variations are constantly changing due to the dynamic language contacts happening in the period of dynamic globalization. It is a reality that gaps are huge between actual language practices and myths about language spread due to dominant ideologies. The case with the Romani language, which is not accepted to have a standard form, is an example of a dominant ideology being always indifferent to the needs of the ethnic groups. This means that its use is not even studied. Recently, there have been attempts of scholars to develop more inclusive approaches to study the use of languages; however, those are still limited to officially recognized languages only. One example is the translingual approach (Horner et al., 2011) which addresses differences within and across all languages. It promotes the idea that the formation and definition of languages and language varieties are fluid and that those differences should be protected and developed further, since they are resources which prove richness and diversity.

Furthermore, there has been a shift in using more critical approaches with the focus on the study of the social, cultural and linguistic changes in the field of sociolinguistics due to globalization, transnational population flows and the changes taking place in the economic and political landscapes of various “Corresponding author: elenarizova@fzf.ukim.edu.mk 
Rizova, E., Bekar, M., \& Velkovski, Z. (2020). Educational challenges of roma minorities: The case of the Republic of North Macedonia, International Journal of Cognitive Research in Science, Engineering and Education (IJCRSEE), 8(3), 113-122.

geographical areas.

In this respect, scholars and teachers should consider seriously what kind of pedagogical possibilities translingualism can offer. When it comes to agency in meaning making, a language that is not recognized to be contributing to agency and to the power relations in a society just exemplifies the matrices of power of the dominant ethnicities and their official languages. Unfortunately, the problem of literacy of ethnicities with least power due to their lowest material and social status is rarely explored. In this paper we borrow the basis of the translingual approaches and include the socio-economic contexts along with all the educational policies and actions made by both governmental and non-governmental organizations in the R. N. Macedonia. Factors responsible for the still low literacy levels among the members of those groups are included. In other words, national strategic plans exist and are being evaluated by various EU organizations. Finances are offered by the European Union with clearly defined objectives. However, these given possibilities do not necessarily improve the state of some of the minorities.

The recommendations and reports from both the EU and the local governmental or nongovernmental organizations should be always compared and combined with the personal narratives of the subjects, as well as with the ethnographic research of the minority groups' beliefs so that the real impact of EU recommendations is measured more realistically. For example, one of the realities is that Romani people in the R. N. Macedonia are not still given the right to receive literacy in their own written language although our country is a signatory to the Convention on the Rights of the Child which guarantees the right to education, children's' own cultural identity, language and values. The Constitution also states that "members of the communities shall have the right to education in their mother tongue in the primary and secondary schools". Nevertheless, the proportion of Roma to continue education beyond compulsory high school is much lower than for the majority populations and discrimination and prejudice are still widespread (Avery and Hoxhallari as cited in Kamberi et al., 2015). At the same time when economic conditions have a negative impact on school achievement (Miskovic and Curcic 2016), poor education is likely to affect income opportunities over the life-course of individuals and families.

To acquire a full picture of multilingualism in countries such as the R. N. Macedonia, it is necessary to describe in details the specificities and uniqueness of the minority languages and the existing communities of minor ethnicities. For example, the same language can have a different status in different areas and can be protected on different levels. It is possible for the same language to be spoken by two minority groups or one national minority group to speak different languages spoken in the country (e.g. Roma people in Macedonia speaking Albanian and Macedonian). All these findings are important when minority group members are educated in a language different from their $\mathrm{L} 1$. Therefore, the relation between the national, linguistic and cultural identity plays the pivotal role in researching literacy in multilingual contexts.

In order to understand better the term "literacy", as well as the reasons for illiteracy in the Republic of N. Macedonia, it is necessary to consider diverse definitions of literacy and to analyze the criteria according to which people are categorized as literate or illiterate in a national context.

According to UNESCO's last provided description of literacy in the Republic of North Macedonia, literacy is directly correlated to formal education. Namely, "persons having completed more than three grades of primary school were considered literate. In addition, literate was a person without school qualification and with 1-3 grades of primary school, if they can read and write a composition (text) in relation to everyday life, i.e. read and write a letter, regardless of the language" (UNESCO Education for all Literacy for life 2006, UNESCO, p. 157). Although Roma children may not be able to write a story in Macedonian, they can tell it and write it in their L1 - Romani; however, they are still considered illiterate according to international definitions and reports. Apart from the above-mentioned criteria, the categorization literate-illiterate is affected by the drop-out rates in elementary schools.

The high drop-out rates are still problematic although some consider this issue was solved with the introduction of financial punishments for parents who do not enroll their children in schools. But if we analyze the success of school children per generation, it can be concluded that the drop-out rates are really high. For example, around 2608 or $10 \%$ of the enrolled elementary school children drop out during the educational process (grades 1-8). (State statistical Institute of Republic of North Macedonia, Issues 2003/2004, 2004/2005, 2005/2006, 2006/2007, 200/2008, 2008/2009, 2009, 2010, 2010/2011). Drop-out students are handicapped in terms of educational qualifications and later they become parents who cannot influence positively on the intellectual development of their children, so the society faces a situation of circulus viciosus (Rizova, 2015). Some of the main reasons for the high drop-out rates, as stated by parents in the interviews, and in official document is that students cannot acquire literacy in their native language and because some of the teachers do not speak the language of the ethnic groups.

What makes the situation more complex is that the definition of literacy offered by UNESCO which is related to the educational levels of individuals does not include the language of instruction in which 
these individuals have to obtain literacy. According to the Constitution of the country, the citizens have the full right to be educated in Macedonian or in the language which is native for the ethnic communities in the country (Albanian, Roma, Bosnian, Serbian, Vlach). However, due to the lack of qualified Romani teachers and the nonexistence of literature written in the Romani language -- due to the global treatment and the status of the language -- the classes are in Macedonian and in some schools in Albanian, on the request of parents. In both cases, that is not the L1 of the students. This factor seriously affects the success of students gaining basic literacy in schools.

\section{Materials and Methods}

In this paper we present the situation with Roma people in European countries including the various factors and then we focus on North Macedonia by exploring the socio-economic, cultural, policy-related factors which have a direct impact on the literacy of this minority group. We used analytical and descriptive methods for addressing all relevant documentation in national and international context that treats literacy in general and specifically literacy among minority groups, bilingualism and Roma population challenges and opportunities for schooling in their mother tongue. We also use a synthesis method to summarize and classify all the gathered data from different sample groups referring to the research hypothesis about conditioned literacy level of Roma pupils and their possibility to learn in their mother tongue.

Literacy acquired at school cannot be approached as a technical skill only. For proponents of new literacy studies, literacy is perceived as multiple, situated and concerned with power relations (cf. Gee, 1996; Street, 1993). Literacy does not refer only to reading and writing skills, but encompasses behaviors, activities, values and beliefs. It is in close relation to social and emphasizes the role of membership of particular groups (Hull and Schultz, 2001). According to Barton, Hamilton and Ivanic (2000), literacy practices alter social practices within groups. Levinson (2007) explored attitudes across age groups, specifically addressing the social reasons for resistance to literacy and proposed that policy makers should consider effects on group membership and ways in which formal literacy can constitute a mechanism for disempowerment.

According to the last Census, in the Republic of North Macedonia there are 53.879 Roma people (2.66\% of the total population). It is suspected that this number is much higher because some of the Roma population living among Albanian and Turkish populations declare themselves under a different ethnic affiliation. Others are embarrassed to be associated with the term "Roma" or "cigan", as an epitome of low social status, poverty and poor education. The Roma population usually inhabits suburban settlements, which are characterized by poor infrastructure and public services, bad living conditions and poor quality of the buildings, as well as unresolved property status/relations. National researches show that there are serious literacy-related problems such as lack of civic documentation which is due to the low level of information, lack of skills among Roma to get well-informed and lack of basic reading and writing skills (Gaber-Damjanovska, 2012).

An indication that the lowest educational levels are dominant among the Roma unemployed people is the fact that of the total number of unemployed Roma, $90.62 \%$ are unqualified workers, i.e. persons with completed primary school at most (Strategy for Roma in the Republic of North Macedonia, 2005). About $75 \%$ of the Roma are unemployed, which is twice as much as the national average, out of whom only $4.4 \%$ finish secondary education. According to a study conducted in 2016 by Step by Step organization, there is a downward trend in Roma enrolment in grade 1, especially between 2005/06 (with 1356 children enrolled in first grade), and 2008/09 (1672) and 2012/13 (961), as well as in the overall enrolment in primary education for the same period, namely from 8409 (2005/06), 10571 (2008/09) to $9874(2012 / 13)$ Roma in primary school (Strategy for Roma in the Republic of North Macedonia 20142020).

In secondary education, there is an encouraging improvement in the enrolment of Roma population. The number has increased from 1240 (2005/06) to 1916 (2012/13). In regard to the participation of girls within the overall student population, in 2012/13 the number of girls in primary education is almost equal to that of boys, but in secondary education girls make up for less than $45 \%$. This data is highly encouraging that in the same year, there are more girls enrolled in first grade than boys, which is to a large part due to the efforts of civil society and government for raising awareness of the importance of education, especially for females.

The second National Strategy for the Roma people in the Republic of North Macedonia (201420) was designed in 2014, with the following goals that should guide the efforts of the Government for improving the situation of Roma in the country. Since the focus in this study is on the literacy-related 
issues and employability, those goals are stated here: (1) to improve the education attainment level of the Roma community; (2) to develop and promote the Roma culture, language and tradition (Strategy for Roma in the Republic of North Macedonia 2014-20); (3) to increase the number of Roma registered in the Employment Service Agency Agency; (4) in the period of 2014-2020, to increase the number of Roma children at preschool age attending pre-school education by $25 \%$; (5) to increase the participation of Roma caregivers in kindergartens by 2020; (6) to cover at least $98 \%$ of Roma children for enrolment in 1 st grade of elementary education and to improve their performance and to achieve a minimum of $75 \%$ transfer from one grade to the next by $2020 ;(7)$ to increase the transition rate from primary to secondary education and improve performance and significantly reduce drop-out of Roma secondary school students by 2020; (8) to increase the number of Roma students enrolled in pedagogical and teacher training; (9) to enable adult Roma to complete primary and secondary education, with the aim of improving opportunities for income, personal development and other needs; (10) to decrease the number of Roma students attending schools for children with special needs by $20 \%$ by 2020 , and finally, (11) to improve publishing of literature in the Romani language and support Roma authors. This long list of priorities shows how many factors have been affecting the literacy of this minority group for a long time.

As stated in the Hornberger contunua model of biliteracy, materials and content are one of the dimensions that help us understand biliteracy better. Under content here we refer to the books written in Romani and the only subject offered in elementary schools which covers Roma language and culture. Roma people (still called Gypsies in some communities) have a history about their origin and the spread of the communities and their language in Europe. This community has started to preserve its language, even the written one, by teaching it to their children through the $A B C$ book in their own language. Romani (or the language of Roma people) has many dialects and it does not have a stable form of writing (Lee, 2007, p. 4). The alphabet of this language has a system which uses the Latin letters, suggested in 1980/1990 by Marcel Couthiade, who created the first ABC. It was approved by the International Romani Union in 1990, at the Fourth World Congress of the Romani language. This spelling so-called "meta-phonology" allows the dialectic variations to be treated on the phonological level as well as the morpho-phonological one (Matras, 2002). With the acceptance of this alphabet, the Roma people have made a big step forward because education, translation, publishing, diplomatic communication, trade, journalism are only possible with existence of a written language. Even though there is an accepted variation of the language that is considered "standard" in the Republic of North Macedonia, there is no unification of the course books used and none of the course books and grammar books that should be used has been verified by the Ministry of Education and Science. The only offered course that addresses the language and culture of Roma people is mandatory elective; however, it was implemented only in three out of 17 elementary schools.

\section{Research methodology and data collection}

One of the main goals of this research is to examine the level of literacy among Roma pupils from the first cycle of primary education (grade 1-4) as well as the difficulties which pupils, their parents and teachers encounter in the process of Macedonian literacy acquisition.

The research used mixed methods, both quantitative and qualitative, because it is based on the results from the test of knowledge of the subject "Macedonian language" intended for the pupils, as well as on the results gained from the questionnaires and semi-structured interviews exploring parents' and teachers' opinions about the challenges and benefits from the whole literacy process. Data from the relevant documentation was also taken into consideration in order to obtain methodological triangulation of the results. The main research hypothesis is that Roma pupils literacy level is conditioned by the possibility to learn in their mother tongue. Several additional, supplementary hypotheses refer to literacy acquisition of Roma pupils and: 1) educational level of their parents; 2) poor living conditions and poverty; 3) teachers competences; and 4) lack of didactic materials in Roma language.

The research techniques and instruments used in order to obtain relevant data were:

- Inquiring, using a Likert-type questionnaire in order to find out the opinions of parents about the challenges and strengths from the process of literacy acquisition of their children;

- Interviewing, using semi-structured interview protocols with illiterate or semi-illiterate parents who were not able to fill-in the written questionnaire. The protocol contained the same topics as the questionnaire;

- Interviewing, using semi-structured interview protocols intended for the teachers about their opinion of challenges and strengths from the process of literacy of Roma pupils and cooperation with their families;

- Tests of knowledge measured in the course subject "Macedonian language" for pupils from grade 1-4. Standardized formal tests were used, the same ones that are used for grading the pupils. 
- Relevant documentation analysis (national and European) which will serve as a theoretical background for the analyses of the obtained results and their placement in the national context of the research.

Table 1

Sample of the research

\begin{tabular}{lc}
\hline \multicolumn{1}{c}{ Sample } & Number $(\mathrm{f})$ \\
\hline Pupils from grade 1-4 & 101 \\
Parents & 50 \\
Teachers & 4 \\
Total & 155 \\
\hline
\end{tabular}

For the purposes of this research 155 participants took part: 101 Roma pupils who attended elementary schools, grade 1 to grade 4, then, 50 parents of the pupils involved in the research, and 4 teachers form the same school who teach to Roma pupils.

The school children who participated in this research were from a local elementary school in Skopje "Brothers Ramiz and Hamid." This is a school where most of the Roma population receives primary education. Furthermore, tests of knowledge from the subject "Macedonian language" were taken into account as well as data from the interviews about the difficulties which they encountered in the process of learning this subject. Parents were interviewed about their opinion of their children's success in the course subject "Macedonian language", as well as their opinion about the educational process in general and their involvement in it. The teachers were asked about the process of learning, success of the pupils and the difficulties Roma pupils encounter while learning.

\section{Results}

The interviews with the teachers in this school, as well as the analysis of the school records and documentation revealed that there is a significant increase of first graders enrolment compared to the past 10 years. However, there is a retention of the students, meaning they do not attend classes regularly. According to the records, $33 \%$ attended the classes regularly, while $67 \%$ missed most of the classes which affected their academic achievement; specifically, the achievements for the course subject "Macedonian language", which is the official language of the country.

- don't attend classes regularly $\square$ attend classes regularly

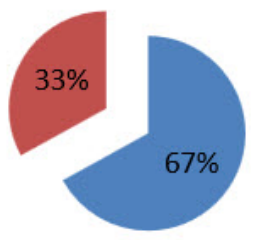

Figure 1. Attendance of Roma pupils in the first cycle of primary education

The additional factor affecting the literacy is that the language of instruction is Macedonian, which is not the first language of the Romani people. The basic literacy acquisition process is affected further because the teachers do not speak Romani, there is a lack of highly educated and trained Roma teachers who speak both languages-Romani and Macedonian. In other words, the situation is that Romani first graders need to acquire basic reading and writing skills in a language they do not even speak.

Although the aims of the first grade curriculum predict recognition and writing of capital letters of the Macedonian alphabet, $89 \%$ of the pupils cannot achieve this aim unlike the Macedonian pupils of whom $99 \%$ manage to reach this goal. The achievements in Math are positive for both Romani and Macedonian pupils because Romani pupils do not need the language while solving mathematical problems. This finding is similar to the Outakoski (2015) about learners and parents conveying attitudinal preferences for the productive and receptive oral skills instead of the productive and receptive writing and reading skills.

In the Republic of North Macedonia, the educational system presupposes becoming fully literate by 
grade three, which means students have to possess basic reading and writing skills, so they can use those skills in a broader context. Findings showed that the results of the Roma pupils in the subject "Macedonian language", even in grade three, are unsatisfactory. Using the official national grading system, the average grade would be 2.5 out of 5 . The description of their abilities accompanying the numerical grade (2) was the following: pupils listen actively, articulate the standard speech partially, read with difficulties and make spelling mistakes when rewriting texts, mixing the cursive and capital letters. In terms of comprehension they partially understand the content of a written text, but are able to respond to questions orally, can follow content for electronic/TV/audio media; however, when retelling and describing orally some of the sentence structures are improper or incomplete.

The interviewed students emphasized the fact that Macedonian was their least favorite subject while Math and Music were their favorite subjects. The responses justifying this feeling most often were "I can't understand the teacher", "The teachers speaks too fast in a language I don't understand" and "There are many letters in the Macedonian alphabet that I can't remember". These statements clearly point to the fact that pupils have a problem with the understanding of the Macedonian language not with the literacy acquiring process per se. If these literacy processes were conducted in the Romani language, i.e. their spoken L1 language, the results would be higher.

Table 2

Answers of Roma pupils about the challenges in acquiring the subject "Macedonian language"

\begin{tabular}{lcc}
\hline \multicolumn{1}{c}{ Statements of pupils } & $\mathrm{F}$ & Percentage \\
\hline I can't understand the teacher & 87 & $86 \%$ \\
Teacher speaks too fast in a language I don't understand & 73 & $72 \%$ \\
There are many letters in the Macedonian alphabet that I can't remember & 79 & $78 \%$ \\
\hline
\end{tabular}

All interviewed parents believed that their children should go to school, learn and develop their fullest potential in order to be able to integrate more easily in mainstream developments in society and on the labor market, which is a positive indication of their awareness of the importance of education. On the other hand, in some other questions they stated that their children do not go to school, because they work on the market or help their mother with the chores. It remains to be seen how this awareness is turned into practical support and creation of a conducive and supportive development environment in the home.

Regarding the main problem with literacy of Roma, poor results were evidenced among pupils in the domains language, communication and literacy, with ascertained poor vocabulary and abilities for expressing thoughts, poor verbal communication with other persons, as well as problems in understanding spoken language, printed symbols and written forms of expression. Specifically, Roma pupils had problems with listening to and understanding spoken language (both Romani and Macedonian), with application of proper speech, proper vocabulary, as well as problems related to the readiness for participation in writing activities. At home, these children speak Romani, but are not exposed to reading and writing both in Romani and Macedonian since most of the parents have obtained only elementary school education and have not developed such literacy behavior of reading to their children, or they have difficulties due to their semi-literacy. A more inclusive and comparative approach to language acquisition should be implemented, which implies recognition of the language of the Roma people and ability of teachers to contrast its nature and forms to the target language taught.

Furthermore, the interviews with the parents and the teacher were divided in eight thematic sections. Here we present responses only from the sections related to education and literacy. The systematic development of the caparbilities and skills of the teacher goes hand in hand with efforts to apply scientific achieve $\urcorner$ ments in teaching based on knowledge and scientific principles. The teacher is the me-diator of the updated knowledge and the one who implements the reforms and changes in the educational process so the teaching requires qualified professional and thorough pedagogical education (Panev and Barakoska, 2015).

In one of the sections titled "Difficulties in the realization of the teaching process to the question Do students understand you when you teach?", few teachers stated that they "must use simple words and sentences due to the pupils' age, but also because pupils do not understand what we are saying." They added that "like it or not, they started learning the language of the Romani." Another teacher pointed out that pupils make a lot of mistakes on dictations, so they "have to lower down the assessment criteria, because everyone will fail." A third teacher added that he is certain that these pupils would achieve better grades if at least one of the teachers was Romani. "They will understand each other better. We are trying, but it is in vain. They start failing and drop-out in grade 5", the teacher pointed out. In regard to basic 
spelling, teachers pointed out that even in grade 3, Roma pupils make many spelling mistakes and if they succeed in acquiring basic literacy by grade 5, the teachers "feel happy." Unfortunately, this is the case with all subjects except for Physical education. Teachers pointed out that there is lack of interest in schooling among Roma pupils.

Another thematic section was titled "Educational stimulation at home". The questions posed to the parents were aimed at eliciting from them whether they helped their children with the homework and whether they read books to them. Most parents stated that they helped if it was in their capacity. One parent stated that usually the older brother helped since he had more education than the parent. As for the home practice of reading books, parents stated "we don't have enough time since we are absent from home, working on the market all day, cleaning and cooking." As an additional burden they pointed out the fact that although the books are gifts from the school "they are written in Macedonian; everything is in Macedonian; even the certificates are in Macedonian." This example adds to previous research that globally power relations place the majority language in a position where it is viewed as superior to and more important than other languages (see Hirvonen, 2008). This creates an inherent power imbalance. Hornberger (1989) presented three models of bilingual education with different outcomes: the transitional, the maintenance and the enrichments model (p. 223). The context of schooling of Romani children and bilingual education is an example of a transnational model in which the minority language is replaced or pushed aside.

The section titled "Participants' perceptions about schooling", aimed at parents, revealed that parents dropped-out from school themselves, because they "had to clean and help their mothers" as they were not good at school. Others stated that they were not allowed by their parents to go to school, so now they feel that their own children deserve better future and must be educated. One mother stated "I told my husband that Ajrula, our son, will not repeat my mistakes. He will go to school. At least now we are given free books."

Opening up of the policies and starting with the bottom-up based practices in the Romani context can help to make new implementation and ideological choices. Such choices can boost the Roma people literacy development and could be used strategically as reinforcements for each other (Hornberger, 1989). From the results one can see that there is a complex interaction between context, content, media and development (Hornberger, 1989) where aspects such as interest for schooling, exposure to literature, interaction with teachers who speak the $\mathrm{L} 1$ of the students seem to interact.

The Continua of Biliteracy model Elias (2010) points out the importance of materials and biliterate content for simultaneous development in language and literacy skills in several languages. Our research by looking at documents and talking to teachers and parents showed that there is only one mandatory elective course/subject "Roma language and culture", aimed at fourth graders, which is more of an effort of the Government to implement it in elementary schools than it has really worked out in practice. The subject was planned to contain material and tasks for development of the listening, speaking, reading and writing skills, as well as with the inductive acquisition of Romani grammar contents. The subject was offered in 12 out of 17 schools and only three of them delivered it. Some parents responded to the question why the subject was not implemented stating there was insufficient interest for an extra subject for which students will be assessed. But talking to teachers it was concluded that parents were not informed on time about the subject because they were doing seasonal work or schools were unable to organize the subject classes due to lack of appropriate teaching staff.

In terms of content of the subject, parents were delighted that students who cannot learn the Romani at home, can finally learn it in schools seeing that as the only possibility to maintain the Roma language and the culture. The grammar, the development of reading and writing skills were important parts of the subject. However, there was a serious problem because there was no official course book verified by the Ministry of Education and Science. Some schools, by personal choice of the teachers used an ABC and a grammar book by Jusuf Shaip or the book Numaj o Lil si amaro amal by Sefgjul Abdula.

The financial situation of Roma families is yet another reason often given why Roma discontinued their schooling. Most of the Roma families are affected by unemployment, poverty and depend on various types of social welfare, which leads to failure to meet the basic existential needs. Educational level is also in line with the employment status of the participants. Namely $99 \%$ of the respondents were unemployed. Of them, $21 \%$ were recipients of social welfare. This is an existence-related indicator which points to possible serious problems that may follow in everyday life, including the physical and material environment in which they, their families and children live. In line with this characteristic is also the information about their living conditions. Only $42 \%$ lived in their own home, while the others lived together with other families/ in extended households (54\%) or in rented properties (4\%). Another common characteristic is the large number of family members (on average 6 members per family), on average 3.2 children per family. This 
significantly affects the time parents can devote to supporting their children's development, on one hand, and also to meeting their own needs or pursuing their educational interests, on the other. Although over $90 \%$ of women and girls stressed the importance of education for their children, they pointed out the traditional views on levels of education among the Roma which among other factors result mainly from the financial barriers. In spite of the fact that the primary and secondary education (including textbooks) is free, mothers stated the need for money for food, clothing, and transportation, which are difficult to secure, especially given that higher than average number of children per family among Roma.

Worrying about meeting ends meet, education is rarely given a priority. In order for these personal aspirations, whether for themselves or for their children, to be realised, it is necessary for all stakeholders in the society who bear responsibility for realization of the human rights of Roma women and children and for addressing their needs for educational and personal development to engage themselves in coordinated meaningful activities both on a national and on a local level.

\section{Discussion}

In regard to national level policies that pertain to supporting local communities in the emancipation of the vulnerable groups of citizens, it is necessary to establish mechanisms that would contribute to increasing the flexibility in implementing measures for assisting this category of citizens. In this way, inclusion of Roma into society would be easier and more efficient.

Currently, nongovernmental sector implements different programming strategies mainly focused on scholarships and tutorship for Roma children and youngsters. Challenges they face are oriented to lack of understanding by the environment, insufficient funding opportunities and lack of cooperation with some local authorities. The main challenge of civil society organizations is that many share similar missions and conduct similar activities, whether in isolation, coordination or collaboration. There is a clear need for state organized actions aimed at improving the information and education levels of the Roma, improvement of the quality of living and strengthening the professional and social competencies of the Roma population, especially children and youth. Even though from a legal point of view, the situation of the Roma people in Europe has improved these past decades, as minority rights (Avery \& Hoxhallari as cited in Elias (2010) to language and culture have been guaranteed. But, despite of legislation and strategic documents being well designed, there is lack of implementation efforts to put "writing into action".

In regard to the domain approaches to learning, the levels of curiosity, initiative, creativity and perseverance were assessed as low, and in the context of absence of a stimulating environment and child development support, it was recommended that programme activities should focus on acquisition of new experiences and learning from experience, encouraging curiosity/readiness to ask questions, and on developing creativity in everyday experiences and activities.

Since poor results were also evidenced in the domains language, communication and literacy, with ascertained poor vocabulary and abilities for expressing thoughts, poor verbal communication with other persons, problems in understanding spoken language and printed symbols and written forms of expression, the recommendations for activities included: 1) listening to and understanding spoken language (Romani and Macedonian), 2) application of proper speech and vocabulary, 3) readiness for participation in writing-related activities and 4) a more inclusive and comparative approach to language acquisition should be implemented which implies recognition of the language of the Roma people and ability of teachers to contrast its nature and forms to the target language taught.

\section{Conclusion}

Our purpose was to examine the level of literacy among Roma pupils from the first cycle of primary education (grade 1-4), as well as the difficulties which pupils, their parents and teachers encounter in the process of literacy acquisition and to explain how the possession of power affects the literacy practices of a minority group (Romani). We claim that its redistribution initiated by educators and policy makers may improve the literacy levels of the minorities. One way is not only to give students the right to speak in their $\mathrm{L} 1$, but also to have subjects that address their cultural values and everyday practices, as well as to be provided with adequate educators who speak Romani. Or as Hornberger (1989) pointed out local actors are actively involved in making use of oral, bilingual resources at the micro-level to change the discourses and practices of discrimination, racism (or in our case segregation and exclusion from main educational practices) to one of collaboration. We need to keep on raising the awareness that most of the problems of Roma children in regard to being successful in schools are closely related to the larger societal processes 
that shape the nature of schooling.

Within minority groups among which are the Roma people, standard literacy is viewed with ambivalence. Some parents were keen on their children having opportunities that were denied to them, there was also a widespread apprehension that literacy skills remove children further from traditional Romani economic and social spheres. Even a survey of 155 participants on the problems they encounter in regard to literacy and in relation to other socio-economic and political factors can give a clear idea about what the reality demands when the perspective of observing literacy of minority ethnicities is brought into dialogue with a perspective that foregrounds the decisions made in societies in regard to a status of a language or a minority group. Although we received responses based on individual accounts, those are not unique, but on the contrary, they revealed much about the specific dimensions of literacy practices, social conditions and ideologies that are neglected when taking assumed results from implemented practices as successful outcomes, without rechecking the conditions in reality by speaking directly to the subjects involved. Exploring situations that have rarely been in focus because they were considered marginal leads to a deeper understanding of literacy practices in diverse socio-economic contexts. Such situations become vital to develop strategies of multilingual understanding.

Only by researching experiences of social and linguistic exclusion and the predetermined status that participants have in relation to unexpected language practices, traditional perceptions and norms, resources, concerns and plans for their offspring, this type of research can contribute to the raising of an awareness of language ideologies and power relations which label certain literacy practices as deficient. Taking the respondents' perspectives apart from official EU reports and Strategy plans by Governments as points of departure helps us avoid the setting of pre-determined categories such as first and official language and the other linguistic realities. We believe this research confirms that relation between the national, linguistic and cultural identity plays the pivotal role in researching literacy in multilingualual contexts.

Literacy practices are dynamic and situated in different dimensions (Street, 2002). They reflect and shape social structures (Barton, Hamilton, and Ivanic 2000). Research shows the situation is one of a choice between survival and identity. Such context imposes significant challenges and dilemmas for the Roma people, teachers and policy makers. There is a need for further, in-depth investigation into the uses of literacy within Roma communities. Re-conception of literacy on institutional and social level may be beneficial for all pupils, not only for the minority groups. This means empowering the disempowered and commitment of all of us to improve literacy levels of individuals from marginalized groups. But unfortunately, many important experiences in Roma educational work remain silent, and significant aspects of practices are not sufficiently shared across contexts (Avery and Hoxhallari, 2017).

We believe that the linguistic heterogeneity of all users of a certain language both locally and globally should be recognized and that any official-language monolingualist expectations should be confronted and challenged by researching and understanding how teachers and policy makers can work with and against the expectations of policy makers and ideologies that prevent bi- and multilingualism. We also believe that much more can be done by developing a broad range of expertise from the educators by organizing joint training sessions and monitoring visits to identify improvement areas and work individually with staff on improving their literacy-transferring performance.

\section{Acknowledgments}

We want to express our deep gratitude to all individuals included in the research, especially students, teachers, principals and other educational staff from the primary school OOU Brakja Ramiz i Hamid - Skopje, as well as the parents of students involved in the survey. We also want to thank our colleagues from other higher education institutions working on same or similar areas that provided their references and consultations during creation of this paper.

\section{Conflict of interests}

The authors declare no conflict of interest.

\section{References}

Avery, H., \& Hoxhallari, I. (2017). From policy to practice: Roma education in Albania and Sweden. The Urban Review, 49(3), 463-477. https://doi.org/10.1007/s11256-016-0394-5

Barton, D., Hamilton, M., \& Ivanic, R. (2000). Situated literacies: Reading and writing in context. Psychology Press. 
Rizova, E., Bekar, M., \& Velkovski, Z. (2020). Educational challenges of roma minorities: The case of the Republic of North Macedonia, International Journal of Cognitive Research in Science, Engineering and Education (IJCRSEE), 8(3), 113-122.

Baynham, M., \& De Fina, A. (Eds.). (2005). Dislocations/relocations: Narratives of displacement. Manchester: St. Jerome.

Brüggemann, C. (2012). Roma education in comparative perspective. Analysis of the UNDP/World Bank/EC Regional Roma Survey, (Bratislava: UNDP, 2012). Retrieved from http://issuu.com/undp_in_europe_cis/docs/education_ web?e=3029457/1363948

Centre for Human Rights and Conflict Resolution (2012). Истражување на појдовната состојба во врска со меѓуетничката интеграција во образованието. [Research on early stages of interethnic integration in education].

Courthiade, M. (2007). La literature des Rromes [Aroma literature], Sintes et Kales, Inalco.

Cvikić, L., Petroska, E., Novak, M. J., Vuković, P., \& Trenevski, T. (2013). Prvi, drugi, ini jezik: Hrvatsko-makedonske usporedbe. [First, second and other language: Croatian-Macedonian comparisons] Zagreb: Hrvatsko filološko društvo.

Elias, S. B. (2010). Regional minorities, immigrants, and migrants: The reframing of minority language rights in Europe. Berkley Journal of International Law (BJIL), 28(1), 261-312. Retrieved from https://digitalcommons.law.yale.edu/student_ papers/79

Fleck, G., \& Rughinis, C. (2008). Come closer. Inclusion and exclusion of Roma in present day Romanian society. Cosima Rughinis.

Gaber-Damjanovska, N. (2012). Housing of the Poor - Focus on Roma in the Republic of Macedonia, for the Habitat Macedonia Project Promotion of the Housing Rights of Roma. Skopje: Habitat for Humanity Macedonia.

Galasińska, A., \& Horolets, A. (2012). The (pro) long (ed) life of a "grand narrative": the case of Internet forum discussions on post-2004 Polish migration to the United Kingdom. Text \& Talk, 32(2), 125-143. https://doi.org/10.1515/text-2012-0007

Gallego, M. A., \& Hollingsworth, S. (Eds.). (2000). What counts as literacy?: Challenging the school standard. Teachers College Press.

Garaz, S. (2014). Helping the marginalised or supporting the elite? Affirmative action as a tool for increasing access to higher education for ethnic Roma. European Educational Research Journal, 13(3), 295-311. https://doi.org/10.2304/ eeri.2014.13.3.295

Gee, J. P. (1996). Social Linguistics and Literacies: Ideology in Discourses (2 $\left.{ }^{\text {nd }} \mathrm{Ed}\right)($ London, Falmer).

Hirvonen, V. (2008). 'Out on the fells, I feel like a Sámi': Is There Linguistic and Cultural Equality in the Sámi School?. In Can Schools Save Indigenous Languages? (pp. 15-41). Palgrave Macmillan, London. https://doi.org/10.1057/9780230582

Hornberger, N. H. (1989). Continua of Biliteracy. Review of Educational Research, 59(3), 271-296. https://doi. org/10.3102/00346543059003271

Horner, B., Lu, M. Z., Royster, J. J., \& Trimbur, J. (2011). Language difference in writing: Toward a translingual approach. College English, 73(3), 303-321. Retrieved from https://ir.library.louisville.edu/cgi/viewcontent.cgi?article=1065\&cont ext=faculty

Hull, G. Schultz, K. (2001). Literacy and learning out of school: A review of theory and research. Review of Educational Research, 71(4), 575-611. https://doi.org/10.3102/00346543071004575

Lu, M. Z., \& Horner, B. (2016). Introduction: Translingual Work. College English, 78(3), 207-218. Retrieved from https://ir.library. louisville.edu/cgi/viewcontent.cgi?referer=https://scholar.google.com/\&httpsredir=1\&article=1062\&context=faculty

Kamberi, E., Martinovic, B., \& Verkuyten, M. (2015). Life satisfaction and happiness among the Roma in central and southeastern Europe. Social Indicators Research, 124(1), 199-220. https://doi.org/10.1007/s11205-014-0783-7

Kresova, N. (2012). Storytelling on Web 2.0: The case of migrants' personal blogs. Narrative Matters.

Lee, R. (2007). Learn Romani: Das-duma Rromanes. Hertfordshire: University of Hertfordshire Press.

Levinson, M. P. (2007). Literacy in English Gypsy Communities: Cultural Capital Manifested as Negative Assets. American Educational Research Journal, 44(1), 5-39. https://doi.org/10.3102/0002831206298174

Matras, Y. (2002). Romani: A linguistic introduction. Cambridge University Press.

Ministry of Labour and Social Policy of Republic of Macedonia, Strategy for Roma in the Republic of Macedonia, (2005). Skopje: Ministry of Labour and Social Policy of Republic of Macedonia.

Ministry of Labour and Social Policy of Republic of North Macedonia, Strategy for Roma in the Republic of Macedonia 20142020, (2014). Skopje: Ministry of Labour and Social Policy of Republic of North Macedonia.

Miskovic, M., \& Curcic, S. (2016). Beyond inclusion: Reconsidering policies, curriculum, and pedagogy for Roma students. International Journal of Multicultural Education, 18(2), 1-14. Retrieved from https://eric.ed.gov/?id=EJ1104920

Murphy, V. A. (2014). Second Language Learning in the Early School Years: Trends and Contexts-Oxford Applied Linguistics. Oxford University Press.

O'Hanlon, C. (2016). The European Struggle to Educate and Include Roma People: A Critique of Differences in Policy and Practice in Western and Eastern EU Countries. Social Inclusion, 4(1), 1-10. http://dx.doi.org/10.17645/si.v4i1.363

Okely, J. (1983). The traveller-gypsies. Cambridge University Press.

Outakoski, H. (2015). Multilingual literacy among young learners of North Sámi: contexts, complexity and writing in Sápmi (Doctoral dissertation, Umeå University).

Panev, V., \& Barakoska, A. (2015). The need of strengthening the pedagogical competences in teaching from the english teachers' perspective. International Journal of Cognitive Research in Science, Engineering and Education (IJCRSEE), 3(1), 43-50. Retrieved from https://ijcrsee.com/index.php/ijcrsee/article/view/74

Rizova, E. (2015). Adults and literacy, Skopje: Faculty of philosophy - Skopje.

Street, B. V. (2002). Literacy and development: Ethnographic perspectives. Routledge.

Szalai, J., \& Schiff, C. (Eds.). (2014). Migrant, Roma and Post-colonial Youth in Education Across Europe: Being'visibly Different'. Springer.

UNESCO Institute for Statistics, (2011). Education Indicators and Data Analyses, UNESCO.

UNESCO (2006). Literacy for Life. EFA Global Monitoring Report. Retrieved from http://unesdoc.unesco.org/ images/0014/001416/141639e.pdf 